\title{
GAMBARAN IMPLEMENTASI PENATALAKSANAAN PENYAKIT DIABETES MELITUS DI PUSKESMAS SINDANG BARANG KOTA BOGOR TAHUN 2019- 2020
}

\author{
Dinda Amalia', Wirda Syari², Sevrima Anggraini ${ }^{3}$ \\ ${ }^{1}$ Konsentrasi Manajemen Pelayanan Kesehatan Program (MPK), Program Studi Kesehatan Masyarakat Fakultas \\ Ilmu Kesehatan Universitas Ibn Khaldun Bogor. Jl. K.H Sholeh Iskandar Raya Km. 2, Kedung Badak, Bogor 16161, \\ Jawa Barat. Email : dindaaa.amalia13@gmail.com \\ 2,3Program Studi Kesehatan Masyarakat Fakultas Ilmu Kesehsatan Universitas Ibn Khaldun Bogor. Jl. K.H Sholeh \\ Iskandar Raya Km. 2, Kedung Badak, Bogor 16161, Jawa Barat.
}

\begin{abstract}
Abstrak
Berdasarkan profil Dinas Kesehatan Kota Bogor Tahun 2018, data kasus penyakit Diabetes Melitus (DM) tertinggi berada di Puskesmas Sindang Barang Kecamatan Bogor Barat yaitu sebanyak 1.775 orang, namun tahun 2018 jumlah cakupan yang dilakukan pemeriksaan DM belum mencapai target. Tujuan penelitian ini adalah untuk mengetahui gambaran implementasi penatalaksanaan penyakit diabetes melitus di Puskesmas Sindang Barang Kota Bogor Tahun 2019-2020. Metode penelitian ini adalah kualitatif. Instrumen yang digunakan adalah wawancara mendalam, observasi, dan telaah dokumen. Informan dalam penelitian ini adalah petugas Puskesmas, kader, dan pasien DM. Variabel penelitian ini terdiri dari variabel input, proses, dan output. Hasil penelitian menunjukan bahwa variabel input belum meratanya SDM karena wilayah yang luas, dana bersumber dari BOK dan JKN dan keuangan saat ini cukup baik, sarana dan prasana belum merata di Posbindu, serta masih ada perbedaan antara teori dengan praktik. Variabel proses masih ditemukan pasien yang tidak jujur ketika diwawancara, saat pendataan warga tidak ada di tempat, masih terdapat pasien yang tidak disiplin terhadap kesehatan tubuhnya, proses rujukan terkadang terjadi antrian, belum meratanya kader untuk mengikuti pelatihan, terkadang Dinkes kehabisan stok penyediaan obat, pencatatan dan pelaporan belum tepat waktu, dan belum terdapat jadwal untuk Dinkes berkunjung ke PKM, serta untuk output masih belum mencapai target 100\% karena banyaknya jumlah sasaran. Kesimpulan penelitian ini adalah penatalaksanaan penyakit DM di Puskesmas Sindang Barang berjalan cukup baik, namun belum maksimal masih ada perbaikan. Maka sebaiknya Puskesmas lebih fokus terhadap proses penatalaksanaan DM agar mencapai target yang ditentukan.
\end{abstract}

Kata Kunci : Penatalaksanaan, Penyakit Tidak Menular, Diabetes Melitus, Puskesmas

\section{PENDAHULUAN}

Diabetes Melitus biasa disebut dengan "silent killer" karena bisa menjadi pembunuh manusia secara diam-diam dan diabetes melitus juga sering disebut dengan "Mother of Disease" karena merupakan pembawa atau induk dari penyakit seperti jantung, stroke, hipertensi, gagal ginjal dan kebutaan (Depkes, 2008).

Berdasarkan data World Health Organization (2016), pada tahun 2014 terdapat dua region yang memiliki peningkatan prevalensi kejadian diabetes melitus yang tinggi yaitu di 
Asia Tenggara dengan jumlah penderita DM dari 4,1\% (17 juta

orang) pada tahun 1980 menjadi 8,6\% (96 juta orang) pada tahun 2014 dan Eastern Mediterranean sebanyak 5,9\% pada tahun 1980 menjadi 13,7\% (43 juta orang) pada tahun 2014. Pada tahun 2015 jumlah penderita DM di dunia sebanyak 415 juta jiwa dan akan meningkat menjadi 642 juta jiwa di tahun 2040.

Menurut World Health Organization (2016), Indonesia pada tahun 2017 menjadi negara dengan jumlah penderita diabetes melitus urutan ke-6 tertinggi di dunia bersama dengan Cina, India, Amerika Serikat, Brazil, dan Meksiko. Indonesia masuk urutan ke-6 dengan jumlah 10,3 juta penderita DM dan akan meningkat pada tahun 2045 dengan jumlah 16,7 juta penderita diabetes melitus. WHO menyebutkan $6 \%$ total kematian pada masyarakat Indonesia dengan semua umur disebabkan oleh penyakit DM.

Jumlah prevalensi kejadian DM di Indonesia terus meningkat. Pada tahun 2007 sebesar 5,7\% menjadi 6,9\% atau sekitar 9,1 juta pada tahun 2013. Lalu pada tahun 2018 meningkat lagi sebesar 8,5\%. Sehingga estimasi jumlah penderita di Indonesia mencapai lebih dari 16 juta (Riskesdas, 2013 dan 2018)

Berdasarkan data profil Dinas Kesehatan Kota Bogor Tahun 2018, data kasus penyakit Diabetes Melitus (DM) tertinggi berada di Puskesmas Sindang Barang Kecamatan Bogor Barat yaitu sebanyak 1.775 orang. Berikut ini rekapitulasi pemeriksaan diabetes melitus di Puskesmas Sindang Barang Kota Bogor Tahun 2015-2018:

Tabel 1. Rekapitulasi Cakupan Pemeriksaan Diabetes Melitus di Puskesmas Sindang Barang Kota Bogor Tahun 2015-2018

\begin{tabular}{|c|c|c|c|c|c|c|c|c|c|c|c|c|c|}
\hline \multirow{3}{*}{ No } & \multirow{3}{*}{ Kelurahan } & \multicolumn{4}{|c|}{ Jumlah Penduduk $\geq 15$ Tahun } & \multicolumn{8}{|c|}{ Cakupan Pemeriksaan Diabetes Melitus } \\
\hline & & \multirow[t]{2}{*}{2015} & \multirow[t]{2}{*}{2016} & \multirow[t]{2}{*}{2017} & \multirow[t]{2}{*}{2018} & \multicolumn{2}{|c|}{$\begin{array}{c}2015 \\
\text { (Target: } \\
25,28 \% \text { ) }\end{array}$} & \multicolumn{2}{|c|}{$\begin{array}{c}2016 \\
\text { (Target: } \\
24,77 \% \text { ) }\end{array}$} & \multicolumn{2}{|c|}{$\begin{array}{c}2017 \\
\text { (Target: } \\
24,28 \% \text { ) }\end{array}$} & \multicolumn{2}{|c|}{$\begin{array}{c}2018 \\
\text { (Target: } \\
23,79 \% \text { ) }\end{array}$} \\
\hline & & & & & & Jml & $\%$ & Jml & $\%$ & Jml & $\%$ & $\mathrm{Jml}$ & $\%$ \\
\hline 1. & $\begin{array}{l}\text { Sindang } \\
\text { Barang }\end{array}$ & 11.114 & 11.114 & 8.514 & 11.305 & 528 & $0,047 \%$ & 368 & $0,033 \%$ & 210 & $0,024 \%$ & 559 & $0,049 \%$ \\
\hline 2. & Bubulak & 10.009 & 10.009 & 8.509 & & 285 & $0,028 \%$ & 150 & $0,014 \%$ & 171 & $0,020 \%$ & 419 & $0,038 \%$ \\
\hline 3. & Situ Gede & 5.853 & 5.853 & 5.853 & 8.628 & 201 & $0,034 \%$ & 104 & $0,017 \%$ & 165 & $0,028 \%$ & 370 & $0,042 \%$ \\
\hline 4. & Marga Jaya & 3.792 & 3.792 & 3.792 & 6.813 & 128 & $0,033 \%$ & 66 & $0,017 \%$ & 146 & $0,038 \%$ & 231 & $0,033 \%$ \\
\hline 5. & $\begin{array}{l}\text { Balumbang } \\
\text { Iaya }\end{array}$ & 7.190 & 7.190 & 6.390 & 8.987 & 232 & $0,032 \%$ & 46 & $0,006 \%$ & 153 & $0,023 \%$ & 196 & $0,021 \%$ \\
\hline Jum & & 37.958 & 37.958 & 33.067 & 46.646 & 1.374 & $0,036 \%$ & 734 & $0,019 \%$ & 850 & $0,025 \%$ & 1.775 & $0,038 \%$ \\
\hline
\end{tabular}

Sumber: Data Profil Puskesmas Sindang Barang Kota Bogor Tahun 2015-2018

Berdasarkan tabel diatas dapat dijelaskan bahwa dari tahun 2015- 2018 cakupan pemeriksaan diabetes melitus belum mencapai target yang telah ditentukan. Misalnya berdasarkan Renstra Dinas Kesehatan Kota Bogor Tahun 2018 target yang telah ditentukan yaitu sebesar 23,79\% tetapi cakupan yang didapatkan oleh Puskesmas Sindang Barang hanya sebesar 0,038\%. Maka dari penjelasan tersebut peneliti ingin melakukan penelitian mengenai "Gambaran Implementasi Penatalaksanaan Penyakit Diabetes Melitus di Puskesmas Sindang Barang Kota Bogor Tahun 2019- 2020”. 


\section{METODE PENELITIAN}

Penelitian ini dilakukan di Puskesmas Sindang Barang Kota Bogor pada bulan FebruariNovember 2020. Jenis penelitian ini merupakan penelitian kualitatif bersifat deskriptif yang diperoleh melalui wawancara mendalam, observasi, dan telaah dokumen. Teknik pengumpulan data meliputi data primer berdasarkan hasil wawancara mendalam dan observasi serta data sekunder berdasarkan dokumen-dokumen. Informan penelitian terdiri dari 13 orang yaitu, 1 orang penanggungjawab Program PTM, 1 orang Kepala Puskesmas, 1 orang Dokter Pelaksana Program PTM, 5 orang Kader Kesehatan, dan 5 orang pasien DM yang berada di wilayah kerja PKM Sindang Barang.

\section{HASIL PENELITIAN DAN PEMBAHASAN}

Berdasarkan hasil penelitian yang telah dilakukan, informan kunci dan informan inti memiliki rentang umur 37-55 tahun yaitu 2 orang yang berpendidikan terakhir S1 yaitu 1 Dokter Pelaksana berumur 38 tahun dengan lama bekerja 7 tahun dan 1 orang penanggung jawab program berumur 46 tahun dengan lama bekerja 11 tahun serta 1 orang yang berpendidikan terakhir S2 yaitu Kepala Puskesmas berumur 54 tahun dengan lama bekerja 11 tahun. Untuk informan pendukung Kader Kesehatan memiliki rentang umur 42- 72 tahun dengan pendidikan terakhir 3 orang tamatan SMP dan 2 orang tamatan SMA serta sudah bekerja rata-rata 10-27 tahun. Untuk informan pendukung pasien diabetes melitus memiliki rentang umur 38-57 tahun.

\section{Input}

\section{a. Sumber Daya Manusia}

Berdasarkan hasil observasi dan wawancara mendalam terkait SDM yang terlibat dalam penatalaksanaan DM di PKM Sindang Barang Bogor berjumlah 11 orang yang bersumber dari Puskesmas dan juga kader kesehatan di wilayah kerja Puskesmas yang berjumlah 5 orang di setiap wilayahnya.

Hasil penelitian ini melalui wawancara dan observasi, sumber daya manusia di Puskesmas Sindang Barang dalam pelaksanaan pelayanan kesehatan penyakit diabetes melitus jika mengacu pada Permenkes yang sudah di sebutkan memang sudah sesuai. Namun dalam pelaksanaannya masih terdapat kendala yaitu jika dinilai dari kecukupan, letak wilayah kerja Puskesmas Sindang Barang yang cukup luas mengakibatkan kurang meratanya sumber daya manusia yang ada serta hambatan lainnya itu keterampilan kader belum merata. Sumber daya manusia selain ada dokter, perawat, tenaga gizi, dan Ahli Teknologi Laboratorium Medik (ATLM). Puskesmas Sindang Barang juga bekerja sama dengan kader kesehatan wilayah untuk membantu pelaksanaan pelayanan kesehatan penyakit diabetes melitus. Maka solusi agar wilayahnya bisa rata tertangani lebih maksimal sebaiknya pihak puskesmas melakukan cara termudah terlebih dahulu diantaranya dengan menghitung analisis beban kerja dari setiap SDM yang ikut serta dalam penatalaksanaan penyakit DM di PKM Sindang Barang serta dibutuhkan pembinaan dan perluasan pengetahuan dan keterampilan sehingga kompetensi yang dimiliki dengan tuntutan dan tantangan masyarakat sebanding. 


\section{b. Dana}

Terkait dengan sumber dana untuk kegiatan yang dilakukan di Puskesmas Sindang Barang yaitu bersumber APBN, APBD, BOK, serta dana mandiri (Operasional PKM dan dana keropak bersumber dari dana komunitas peserta Posbindu) dan untuk keadaan dana saat ini sudah mencukupi. Hal ini sesuai dengan Permenkes No 75 tentang Puskesmas yang menyebutkan bahwa anggaran di Puskesmas bersumber dari anggaran pendapatan dan berlanja daerah (APBD), anggaran pendapatan dan Belanja Negara (APBN), dan sumber lain yang sah dan tidak mengikat. Hal ini sejalan dengan penelitian yang dilakukan oleh Zahro (2017) bahwa sumber dana yang tersedia dari BOK dan juga JKN.

Untuk melakukan pencairan dana pihak Puskesmas Sindang Barang harus melakukan beberapa proses yang cukup panjang mulai dari mengajukan kegiatan ke Kepala Puskesmas hingga disebutkan SPJ untuk diverifikasi, baru dana yang dibutuhkan bisa cari.

\section{c. Sarana dan Prasarana}

Berdasarkan hasil dari observasi, wawancara, dan telaah dokumen yang didapatkan mengenai sarana dan prasarana dalam pelaksanaan pelayanan kesehatan penyakit diabetes melitus diantaranya berupa alat ukur (tinggi badan, berat badan, lingkar perut, glukometer, tensimeter, dsb), bahan habis pakai (sarung tangan, striptes gula darah, kapas alkohol, lencet untuk pengukuran gula darah atau kolesterol, masker, dan safety box), leaflet, ruang periksa, buku pencatatan, dsb. Untuk jumlah sarana dan prasarana di Puskesmas Sindang Barang sudah mencukupi dan sesuai dengan Petunjuk Teknis Pos Pembinaan Terpadu Penyakit Tidak Menular (Posbindu PTM) menurut Kemenkes RI Tahun 2012.

Hasil penelitian mengenai sarana dan prasarana untuk mendukung penatalaksanaan penyakit diabetes melitus belum semua posbindu mendapatkan alat posbindu kit dari pemerintah dan untuk alat kesehatan yang digunakan dalam penatalaksanaan penyakit diabetes melitus ini kebanyakan sudah model digital yang menyebabkan beberapa kader kesehatan belum paham untuk mengoperasikan alat kesehatan tersebut.

Sebaiknya setiap posbindu yang memiliki alat posbindu kit maupun yang tidak memiliki alat posbindu kit membuat kartu absen untuk peminjaman posbindu kit ke posbindu lainnya dan juga membuat jadwal tertentu untuk peminjaman agar tidak terjadi bentrok waktu.

\section{d. Metode}

Berdasarkan informasi yang di dapat bahwa untuk pelaksanaan pelayanan kesehatan penyakit diabetes melitus di Puskesmas Sindang Barang sudah menggunakan pedoman atau acuan yang bersumber dari Kemenkes mengenai penyakit tidak menular diantaranya Peraturan Menterei Kesehatan RI Nomor 43 Tahun 2016 tentang Standar Pelayanan Minimal Bidang Kesehatan, Peraturan Menteri Kesehatan Nomor 71 Tahun 2015 tentang Penyakit Tidak, Pedoman Teknis Penemuan dan Tatalaksana Penyakit Diabetes Melitus Tahun 2008, Pedoman Pengendalian Diabetes Melitus dan Penyakit Metabolik Tahun 2008, dan Petunjuk Teknis Posbindu Kader Tahun 2019. hambatan yang terjadi pada metode ini diantaranya adalah terjadinya perbedaan antara teori dengan yang terjadi dilapangan, belum mencapai target SPM. Hambatan yang terjadi pada metode ini diantaranya adalah terjadinya perbedaan antara teori dengan yang terjadi dilapangan, belum mencapai target SPM. 


\section{Process}

\section{a. Pendataan Penderita DM}

Hasil dari wawancara mendalam bahwa untuk mengetahui pendataan penderita diabetes melitus Puskesmas Sindang Barang yaitu dengan melakukan kegiatan skirining yang diadakan di setiap masing-masing Posbindu bersama kader kesehatan. Proses yang pertama menyebarkan kuesioner ke seluruh warga wilayah kerja Puskesmas Sindang Barang yang berusia $\leq 15$ tahun. Kuesioner tersebut diantaranya berisikan identitas responden, riwayat penyakit, pola hidup, berat badan, tinggi badan, lingkar perut, dan IMT. Setelah dilakukan penyebaran kuesioner untuk menentukan sasarannya adalah 2\% dari total keseluruhan sasaran.

Hasil penelitian menyebutkan bahwa pada proses pendataan petugas mengalami hambatan yaitu data yang diperoleh kurang akurat, kadang masih ada responden yang tidak menjawab dengan jujur, serta pada saat pendataan warganya tidak ada di tempat.

\section{b. Skrining Faktor Risiko DM}

Hasil wawancara mendalam di ketahui bahwa untuk melakukan skrining faktor risiko diabetes melitus di Puskesmas Sindang barang ini diantaranya mulai dari isi identitas, wawancara, pengukuran tinggi badan, berat badan, edukasi. Skrining ini juga selain di posbindu atau di PKM dilakukan juga dengan adanya mobil curhat.

Dari hasil informasi yang didapat bahwa untuk pencapaian skrining faktor risiko diabetes melitus di Puskesmas Sindang sampai saat ini belum optimal karena sasaran yang banyak dengan wilayah kerja yang luas. Menurut penelitian Kurniawati (2019) menyatakan bahwa agar sasaran bisa mencapai target sebaiknya sebelum hari-H kegiatan skrining dilakukan, baiknya melakukan sosialisasi terlebih dahulu kepada masyarakat dengan menggunakan pengeras suara di masjid. Jika sosialisasi dengan pengeras suara kurang efektif bisa dengan cara lain yaitu dengan menggunakan metode undangan untuk masyarakat sasaran.

\section{c. Penatalaksanaan DM}

Berdasarkan hasil wawancara menjelaskan bahwa Puskesmas Sindang Barang sudah melakukan intervensi farmakologis semaksimal mungkin. Langkah awalnya dengan adanya kegiatan posbindu nanti ketahuan siapa yang berisiko faktor diabetes melitus nanti akan di sarankan untuk berobat ke Puskesmas. Setelah itu di Puskesmas jika pasien membutuhkan intervensi farmakologis, maka dokter Puskesmas Sindang Barang akan memberikannya. Jika sudah dilakukan pengobatan jangka pendek namun hasilnya tidak membaik maka akan dilakukan rujukan untuk pengobatan jangka panjang ke rumah sakit. Untuk kendala yaitu masih ada pasien yang belum disiplin dari segi pola makan, aktivitas fisik, dan kontrol semaunya karena jarak yang jauh. Menurut penelitian Fajrunni'mah (2017) menyatakan bahwa faktor yang mendorong agar penderita diabetes melitus disiplin dalam manajemen diri salah satunya dengan faktor sosial yang meliputi dukungan keluarga, kedekatan hubungan dengan tenaga kesehatan, serta sharing group sesama penderita diabetes melitus. Dengan adanya dukungan yang baik dari keluarga bisa membuat penderita diabetes melitus 
meningkatkan kepatuhan terhadap penyakit yang di deritanya.

\section{d. Melakukan Rujukan ke FKRTL}

Berdasarkan hasil penelitian diketahui bahwa terkait alur rujukan pasien diabetes melitus yang dilakukan di Puskesmas Sindang Barang sudah sesuai dengan Pedoman Teknis Penemuan dan Tatalaksana Diabetes Melitus tahun 2008. Puskesmas akan melakukan rujukan apabila pasien tersebut sudah tidak bisa ditangani oleh Puskesmas.

Informasi yang diperoleh dari wawancara terhadap pasien mengenai proses rujukan di Puskesmas Sindang Barang masih terdapat sedikit hambatan pada saat pasien banyak mengakibatkan terjadinya pasien menjadi antri. Maka sebaiknya untuk menghindari terjadinya antrian pihak Puskesmas bisa melakukan mengatur ulang jadwal kunjunga kepada pasien.

\section{e. Pelatihan Teknis}

Hasil wawancara yang telah dilakukan bahwa semua petugas puskesmas maupun kader kesehatan telah mendapatkan pelatihan terkait penatalaksanaan penyakit kesehatan diabetes melitus yang diadakan oleh Dinas Kesehatan Kota Bogor dan Kemenkes walaupun tidak semua kader kesehatan mendapatkan pelatihan. Pelatihan yang diberikan diantaranya tentang pola hidup sehat untuk penderita diabetes melitus, komplikasi diabetes, cara pemakaian alat, dan pengetahuan tentang PTM. Untuk jangka waktu pelatihan yang diberikan setiap 2-3 kali dalam setahun tetapi untuk pelatihan kader kesehatan sudah 2 tahun ini tidak ada. Kader yang di undang untuk mengikuti pelatihan tersebut berjumlah 2 orang sebagai perwakilan dari masing-masing posbindu PTM.

Hal ini sejalan dengan Kemenkes RI tentang Petunjuk Teknis Posbindu PTM (2012) yang menyatakan bahwa pelatihan adalah kegiatan memberikan pengetahuan tentang PTM, faktor risiko, dampak dan upaya yang diperlukan dalam pencegahan dan pengendalian PTM, memberikan kemampuan dan keterampilan dalam memantau faktor risiko PTM dan melakukan konseling serta tidak lanjut lainnya.

Terdapat kendala pada saat pelatihan teknis yang dimana dalam mengikuti pelatihan yang diikuti oleh kader kesehatan hanya bisa diikut sertakan perwakilan saja yaitu 2 orang dan yang mengikuti pelatihan tersebut tidak di rolling mengakibatkan informasi yang didapatkan dari pelatihan kepada kader kesehatan yang lainnya tidak tersampaikan dengan maksimal karena pemahaman setiap kader yang tidak sama. Dari hal tersebut sebaiknya untuk pelatihan selanjutnya dicoba untuk merolling peserta pelatihan agar semua kader mempunyai pengalaman dalam mengikuti pelatihan dan juga menambah wawasan serta keterampilan secara merata.

\section{f. Penyediaan Obat Diabetes Melitus}

Terkait dengan proses penyediaan obat diabetes melitus yaitu pihak Puskesmas melakukan pengajuan ke Dinas Kesehatan setiap 2-3 bulan sekali melalui Laporan Pemakaian dan Lembar Permintaan Obat (LPLPO). Dalam melakukan pemenuhan penyediaan obat diabetes melitus ini pihak puskesmas mengalami kendala yaitu kadang obat dari Dinas Kesehatan Kota Bogor sedang tidak tersedia, maka puskesmas akan membuat resep obat 
kepada pasien untuk membeli di apotek luar.

Menurut penelitian yang dilakukan oleh Kurniawati (2019) menyatakan bahwa ketersediaan obat untuk diabetes melitus juga terbatas yang menyebabkan puskesmas menerapkan sistem 10-15 hari sekali untuk pengambilan obat. Hal tersebut berpengaruh terhadap rutinitas pasien dalam pengambilan dan konsumsi obat.

\section{g. Pencatatan dan Pelaporan}

Pencatatan dan pelaporan di Puskesmas Sindang Barang sudah cukup lengkap karena format yang di cantumkan bersumber dari Kemenkes, tetapi untuk format pelaporannya tidak ada format khusus melainkan menyatu dengan PTM lainnya. Pencatatan dan pelaporan hasil kegiatan penatalaksanaan pelayanan kesehatan penyakit diabetes melitus antara lain ada hasil wawancara faktor resiko PTM, hasil pengukuran faktor PTM, jumlah sasaran setelah semua selesai laporan di berikan kepada petugas kader kesehatan secara manual dengan mengisi form faktor resiko PTM lalu di laporkan ke petugas Puskesmas. Setelah di laporkan ke Puskesmas nanti programmer merekap semua laporan dari kader serta dari kunjungan Puskesmas setalah itu di laporkan ke Dinas Kesehatan Kota Bogor.

Berdasarkan hasil penelitian yang telah dilakukan bahwa pencatatan dan pelaporan hasil kegiatan penatalaksanaan pelayanan kesehatan penyakit diabetes melitus sudah dilaporkan sesuai dengan acuan Kemenkes hanya saja terdapat hambatan untuk pelaporannya masih belum tepat waktu.

\section{h. Monitoring dan Evaluasi}

Hasil penelitian yang didapat, Puskesmas Sindang Barang sudah melakukan pengelolaan dengan cukup baik dan melaporkan semua jenis pelaporan dengan format yang sudah ditentukan. Selain itu monev yang dilakukan oleh Puskesmas Sindang Barang yaitu setiap 3 bulan sekali pihak Puskesmas berkumpul di Dinas Kesehatan Kota Bogor sedangkan dari pihak Dinas Kesehatan Kota Bogor melakukan supervisi ke Puskesmas Sindang Barang setiap 1 tahun sekali yang dilakukan bulan November. ada berbagai macam jenis laporan yang dilakukan oleh Puskesmas Sindang Barang dalam penatalaksanaan penyakit diabetes melitus diantaranya ada pelaporan SP2TP, laporan surveilans PTM, dan sistem informasi P-Care JKN. Laporan tersebut sebagai salah satu untuk melakukan monitoring dan evaluasi.

Terdapat hambatan dalam monitoring dan evaluasi yaitu kurang disiplinnya kader karenan tidak segera untuk mencatat pelaporan secepatnya mengakibatkan pelaporan tidak tepat waktu dan juga dari pihak Dinas Kesehatan untuk melakukan kunjungan ke Puskesmas masih belum terjadwal. Sebaiknya untuk mengatasi hambatan ini pada saat akan laporan pihak Puskesmas lebih teliti lagi sebelum laporan dilakukan untuk meng-cross check semua data- data yang akan dilaporkannya serta selalu di ingatkan kembali kepada Kader untuk segera melakukan pelaporan tepat waktu.

\section{Output}

\section{Capaian cakupan pelayanan kesehatan penderita diabetes}

Berdasarkan hasil informasi yang didapat bahwa untuk perhitungan angka pencapaian pelayanan kesehatan penderita diabetes melitus di Puskesmas Sindang Barang 2\% menurut 
Riskesdas. Sedangkan angka pencapaian untuk tahun ini belum bisa terhitung karena masih proses dalam perhitungan. Jika dilihat dari pencapaian tahun 2019 yang tercapai baru 90\% dari target $100 \%$ sesuai dengan Standar Pelayanan Minimal.

Berdasarkan hal tersebut maka disarankan agar bisa mencapai target $100 \%$ harus lebih di fokuskan lagi mulai dicoba untuk menghitung beban kerja, alat posbindu kitnya segera dilengkapi untuk posbindu yang belum mendapatkannya, lebih di sosialisasikan lagi untuk pendataan dan skrining DM agar masyarakat di wilayah paham maksud dan tujuannya dari kegiatan tersebut, pelatihannya untuk kader kesehatan harus lebih di gencarkan lagi dan dilakukan perollingan peserta agar kemampuan dan keterampilan kader bisa merata, evaluasi lagi untuk waktu pelaporan agar bisa tepat waktu, dan untuk kegiatan kunjungan Dinkes ke Puskesmas sebaiknya pihak Puskesmas harus siap sedia kapanpun jika pihak Dinkes berkunjung ke Puskesmas.

\section{KESIMPULAN}

Bisa ditarik kesimpulan bahwa untuk gambaran implementasi penatalaksanaan penyakit diabetes melitus di Puskesmas Sindang Barang Kota Bogor Tahun 2019-2020 sudah berjalan cukup baik hanya saja belum maksimal masih ada komponen yang harus diperbaiki lagi.

\section{DAFTAR PUSTAKA}

Departemen Kesehatan RI. (2008). Pedoman Pengendalian Diabetes Melitus dan Penyakit Metabolik. https://extranet.who.int/ncdccs/Data/IDN_D1_Diabetes\%20guidlines.pdf (Diakses pada 23 Januari 2020).

Departemen Kesehatan RI. (2008). Pedoman Teknis Penemuan dan Tatalaksana Penyakit

Diabetes Melitus. Jakarta. https://www.scribd.com/doc/167617732/Pedoman-

Pengendalian-DM (30 Januaari 2020).

Dinas Kesehatan Kota Bogor. (2018). Profil Dinas Kesehatan Kota Bogor. Bogor: Jawa Barat.

Eryando, T., Ariha, D., Damayanti, Y. F., Anggraini, S. (2020). Relationship of Age, Working and

Education With/Regarding the Quality of Live of Elderly. 1st International Conference on Science, Health, Economics, Education and Technology (ICoSHEET 2019). Doi: https://doi.org/10.2991/ahsr.k.200723.058

Fajrunni'mah, Rizana et al. (2017). Faktor Pendukung dan Penghambat Penderita Diabetes

Melitus dalam Melakukan Pemeriksaan Glukosa Darah. Jurnal. Politeknik Kementerian Kesehatan Jakarta III.

Kemenkes RI. (2012). Petunjuk Teknis Pos Pembinaan Terpadu Penyakit Tidak Menular (Posbindu PTM). Jakarta. http://www.p2ptm.kemkes.go.id/dokumen-ptm/petunjukteknis-pos-pembinaan-terpadu-penyakit-tidak-menular-posbindu-ptm (Diakses pada 2 November 2019).

Kementerian Kesehatan RI. (2019). Petunjuk Teknis Pos Pembinaan Terpadu (POSBINDU) Bagi Kader. Jakarta: Kemenkes RI. http://p2ptm.kemkes.go.id/uploads/VHcrbkVobjRzUDN3UCs4eUJ0dVBndz09/2019/03 /Petunjuk_Teknis_POSBINDU_Bagi_Kader.pdf (Diakses 11 Februari 2020).

Kurniawati, Nur et al. (2019). Evaluasi Program Pengendalian Diabetes Melitus Pada Usia 
Produktif di Puskesmas Sapuran. Jurnal. Universitas Diponegoro.

N Lisnawati, SK Parinduri, W Syari. (2020). ANALISIS STRATEGI PELAKSANAAN PENEMUAN DAN TATALAKSANA PNEUMONIA PADA BALITA DI PUSKESMAS BOGOR UTARA TAHUN 2018. PROMOTOR 3 (5), 488-500.

Permenkes RI. (2014). Peraturan Menteri Kesehatan Republik Indonesia Nomor 75 Tahun $2014 \quad$ Tentang Puskesmas. Jakarta: Permenkes RI. http://hukor.kemkes.go.id/uploads/produk_hukum/PMK\%20No.\%2075\%20ttg\%20Pu skesmas.pdf (Diakses pada 28 Oktober 2019)

Permenkes RI. (2015). Peraturan Menteri Kesehatan Nomor 71 Tahun 2015 Tentang Penyakit Tidak Menular. Jakarta: Permenkes RI. http://hukor.kemkes.go.id/uploads/produk_hukum/PMK_No._71_ttg_Penanggulangan_ Penyakit_Tidak_Menular_.pdf (Diakses 10 Januari).

Permenkes RI. (2016). Peraturan Menteri Kesehatan Republik Indonesia Nomor 43 Tahun 2016 tentang Standar Pelayanan Minimal Bidang Kesehatan. Jakarta: Permenkes RI. https://djsn.go.id/storage/app/uploads/public/58d/486/f01/58d486f010a3f0671086 47.pdf (Diakses 23 Januari 2020).

Riskesdas. (2013). Pusat Data dan Informasi Kementerian Kesehatan Republik Indonesia: Jakarta.

RI Fisabilillah, W Syari, SK Parinduri. (2020). GAMBARAN PELAKSANAAN MANAJEMEN PELAYANAN POSKESTREN (POS KESEHATAN PESANTREN) DI PONDOK PESANTREN DAARUL RAHMAN 3 KOTA DEPOK TAHUN 2020. PROMOTOR 3 (5), 501-511.

S Zavihatika, W Syari, TN Prastia. (2020). ANALISA KEBUTUHAN TENAGA KERJA RADIOLOGI DILIHAT DARI BEBAN KERJA DI INSTALASI RADIOLOGI RUMAH SAKIT ISLAM BOGOR TAHUN 2020. PROMOTOR 3 (5), 522-529.

Umam, A., Syari, W., Nurdiansyah, A., Sholeha, A. (2020). Peningkatan dan Pemberdayaan Manusia Cekatan (Cerdas, Kreatif, Akhlakul Karimah, Terampil, Sehat dan Mandiri) Melalui Pendidikan Nonformal di Desa Sibanteng. Abdi Dosen: Jurnal Pengabdian Pada Masyarakat 4 (2), 139-145.

UPTD Puskesmas Sindang Barang. (2018). Profil Puskesmas Sindang Barang Kota Bogor. UPTD Puskesmas Sindang Barang Kota Bogor.

W Syari. (2021). PENYULUHAN PENERAPAN GAYA HIDUP MINIM SAMPAH DI DESA SIBANTENG, KECAMATAN LEUWISADENG, KABUPATEN BOGOR. PROMOTOR 4 (1), 3639

W Syari, M Nadjib, D Ranuhardy. (2020). "Evaluasi Ekonomi Parsial antara Pemberian Terapi Rivaroxaban dan Terapi Kombinasi (Unfractionated Heparin+ Warfarin) untuk Pengobatan Trombosis Vena Dalam pada Pasien Kanker di ...". Jurnal Ekonomi Kesehatan Indonesia 5 (1).

World Health Organization (WHO). (2016). Global Report on Diabetes. France: World Health Organization.

Zahro, Fatimatuz. (2017). Kajian Pelaksanaan Standar Pelayanan Minimal Penderita Diabetes Melitus di Puskesmas Silo 1 dan Puskesmas Kencong. Skripsi. Universitas Jember. 